\title{
ZONE STATISTICS OF THE OCEANIC PRIMARY PRODUCTIVITY FOR THE TRADITIONAL FISHING AREAS OF THE OPEN SOUTH CHINA SEA BASED ON MODIS PRODUCTS
}

\author{
ZHOU, W. F. ${ }^{1 *}-\mathrm{XU}$, H. Y. ${ }^{1,2}-$ LI, A. Z. ${ }^{1,2}-$ JI, S. J. ${ }^{1}$ \\ ${ }^{1}$ Key Laboratory of Fishery Resources Remote Sensing and Information Technology, East China \\ Sea Fisheries Research Institute, Chinese Academy of Fishery Sciences, 200090 Shanghai, China \\ ${ }^{2}$ College of Marine Sciences, Shanghai Ocean University, Shanghai 201306, China \\ *Corresponding author \\ e-mail: zhou_wf@hotmail.com \\ (Received $28^{\text {th }}$ Oct 2016; accepted $28^{\text {th }}$ Feb 2017)
}

\begin{abstract}
The South China Sea is one of the most important fishing grounds in China and is also a traditional fishing ground. In order to determine the primary productivity products suitable for various traditional fishing areas, this paper is based on three models of VGPM, Eppley-VGPM and CbPM, we estimate the primary and the average monthly data of marine primary productivity in 8 days, a detailed analysis of the differences in 2006-2015 of these products which the traditional fishing areas in the South China Sea on the interannual and seasonal variation and spatial distribution. The results showed: 1) the years of large interannual variability which three models are estimated to obtain are between 2008 and 2012. At the same time, it has been found that these 5 years is also a frequent occurrence of ENSO events, but the specific regulatory mechanisms need to be further studied, 2) data products estimated by each model which reflected the seasonal pattern of each fishing area have inconsistency, 3) the three models can be used to estimate the characteristics which the coastal and estuarine areas are higher than the open sea area, and deep sea basin is the lowest in space, however the NPP values estimated by the three models are quite different, and the highest estimated value is by Eppley-VGPM model.
\end{abstract}

Keywords: interannual variability; seasonal variability; spatial distribution; optimal model comparison; traditional fishing area

\section{Introduction}

The South China Sea (SCS) is rich in fishery resources as the largest epicontinental sea in China (Qiu et al., 2008; Zhang et al., 2015), and has formed three traditional fishing areas including north, middle and south fishing area (Chu et al., 2002). And estimating oceanic primary productivity from satellite data becomes more and more significant for areas with large spatio-temporal scale (Lee et al., 2015). While there are some unknown problems that if there are differences or how about the goodness of fit among products generated by different sensors, inversion algorithms or estimation models (Liao et al., 2014), which must be considered before choosing which kinds of NPP products as the SCS's research materials. Because of existing some differences between inversion algorithms of different sensors, it is difficult to make comparative studies among NPP results estimated by different models and data sources. Thus it is necessary to do an intercomparison work among NPP products estimated by different kinds of models based on same remote sensing inversion data in the SCS for understanding comprehensively 
differences of these products as well as the causes of these differences and choosing the appropriate product as research data.

Although the estimation works of NPP in different sea areas were done by multiple kinds of models from remote sensing, and homologous field validation studies were accomplished (Campbell et al., 2002; Carr et al., 2006; Saba et al., 2010, 2011; Lee et al., 2015). For instance, ocean primary production estimated by twelve algorithms from surface chlorophyll, temperature and irradiance was compared with daily production derived by ${ }^{14} \mathrm{C}$ uptake measurements in the second Primary Productivity Algorithm Round Robin (PPARR) activity, and the opinion that the performance of different models were independent of the algorithms' complexity was presented (Campbell et al., 2002). Then Scholars had done a comparison of global estimates of marine primary production from ocean color, which showed that current models were challenged by some special factors (Carr et al., 2006). But these field validation data are limited to the coverage in space and time (Liao et al., 2014), which can not provide a criterion of magnitude for the SCS's NPP. These previous studies showed that the differences among estimation of NPP existed in their studying area, and there is no complete comparative research of NPP products in the SCS.

The oceanic primary products, such as NPP products estimated by standard Vertically Generalized Production Model (Standard VGPM), an "Eppley" version of the VGPM (Eppley-VGPM) and Carbon-based Production Model (CbPM) based on MODIS inversion data, have been compared to discuss the annual and seasonal variation of the whole open South China Sea (Xu et al., 2017) . The Standard VGPM just is the original VGPM, which is a common chlorophyll-based algorithm used to estimate regional and global ocean NPP (Behrenfeld et al., 1997). Eppley-VGPM employs basic model structure and parameterization of VGPM. The only difference is that the Standard VGPM uses polynomial relationship, which is replaced with the exponential relationship described by Morel and Eppley for Eppley-VGPM to describe temperature-dependent photosynthetic efficiencies (Behrenfeld et al., 1997; Eppley et al., 1972; Morel, 1991). The CbPM is a carbon-based model, which estimates NPP by retrieving the satellite chlorophyll and the particulate backscattering coefficients to estimate phytoplankton carbon biomass for ocean NPP estimation (Behrenfeld et al., 2005; Westberry et al., 2008).

This paper aims at doing a zone statistics for the existing ocean NPP products estimated by the three models from MODIS data based on the units of traditional fishing areas of the SCS, and doing some analysis of their differences and the cause of the differences in the SCS in order to improve the ocean NPP estimation algorithms and provide a reference for the data filtering and application.

\section{Materials and methods}

Traditional fishing area of the SCS was taken as basic statistical unit in this paper (Figure 1). In order to eliminate difference generated by longitude, north and Middle fishing areas were divided into east and west two parts, respectively. Therefore, the studying areas include western part of north fishing area $\left(17.5-22^{\circ} \mathrm{N}, 106^{\circ}-113.5^{\circ} \mathrm{E}\right)$, 
eastern part of north fishing area $\left(19.5-23^{\circ} \mathrm{N}, 113.5^{\circ}-121^{\circ} \mathrm{E}\right)$, western part of middle fishing area $\left(10-17.5^{\circ} \mathrm{N}, 106.5^{\circ}-113.5^{\circ} \mathrm{E}\right)$, eastern part of middle fishing area $\left(9.5-19.5^{\circ} \mathrm{N}, 113.5^{\circ}-120^{\circ} \mathrm{E}\right)$ and southern fishing area $\left(2.5-10^{\circ} \mathrm{N}, 106^{\circ}-117^{\circ} \mathrm{E}\right)$.

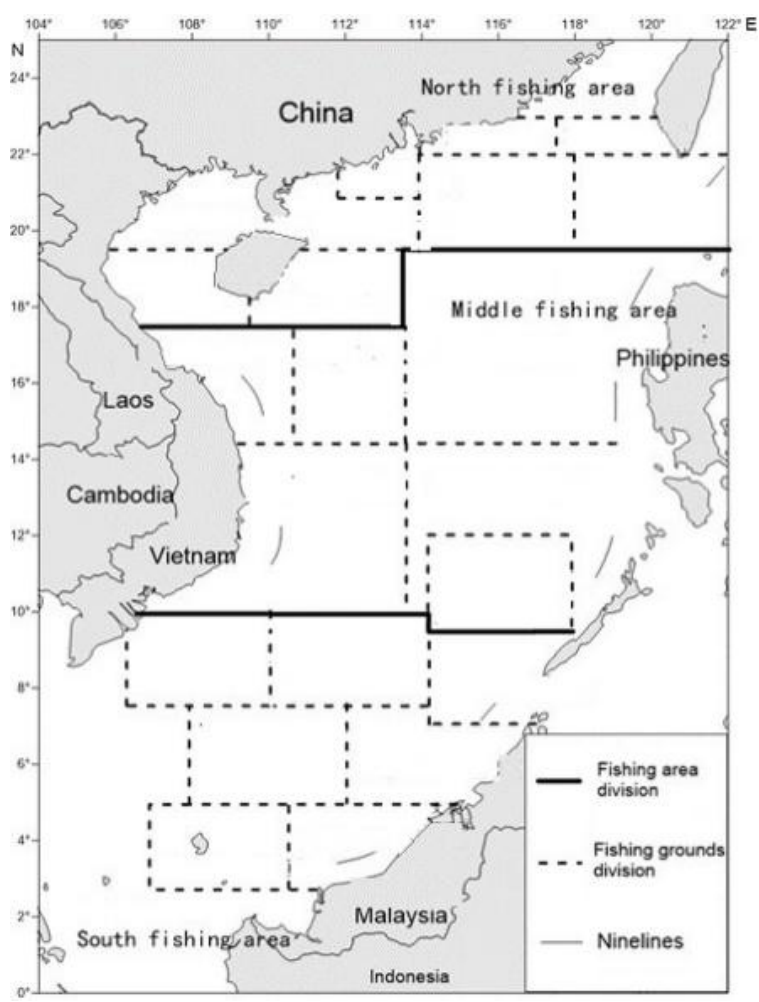

Figure 1. Traditional fishing area in the SCS

The global ocean NPP data products estimated based on MODIS are from the website of the Oregon State University College of Science. The time span of data is from 2006 to 2015 , and the spatial resolution is $1 / 6^{\circ}$. Here we employed 8 days and monthly average ocean NPP data.

The global NPP data with HDF format were preprocessed including reading, image cropping, invalid values removing and calculating average in MATLAB, which were cropped in accordance with the scope of the studying area. The following text is the program code to preprocess the NPP product for one model and western part of north fishing area:

Program of data preprocessing

for year=2006:2015;

for count=1:46;

filename $=\left[\right.$ the path of the stored datalNPP product files name. $\left.\mathrm{hdf}^{\prime}\right]$;

end $\operatorname{npp}(:$, :,count $)=$ hdfread(filename,'npp');

$\mathrm{npp}(\mathrm{npp}==-9999)=\mathrm{nan}$

npp_mean $(:$, :,year-2005)=nanmean $(n p p, 3)$; end

Studyingarea_npp(:, :,year-2005)=npp_mean $(408: 435,1716: 1761$,year-2005); 
We used MATLAB to calculate interannual averages within ten years for the three models products in five fishing areas. The annual variation, the average differences in seasonal differences of the ocean NPP in the SCS were analyzed by diagram (Liao et al., 2014). Distributes comparison for annual high NPP and low NPP in different fishing areas of the SCS were presented by ArcGIS.

\section{Results}

In the western part of the north fishing ground (Fig. 2a), interannual variability presented fluctuation distribution with obvious peaks and troughs. The estimated daily NPP average within one year of the three models peaked in 2008 and 2013. The estimated values of the three models have significant differences. The NPP values estimated by Eppley-VGPM model were the highest and the NPP values by CbPM model were the lowest. The fluctuation changes of this three models were inconsistent during 2006-2015. The values of the VGPM model show peaks in 2008, 2011 and 2013, and the trough appears in 2012, and difference of NPP values by this model were very small, evenly distributed in the range of $1012 \sim 1179 \mathrm{mg} \mathrm{C} / \mathrm{m}^{2} \mathrm{~d}$. The NPP values by Eppley-VGPM model exceeded $1500 \mathrm{mg} \mathrm{C} / \mathrm{m}^{2}$ in 2008 and 2013-2015, and the average NPP in other years is around $1400 \mathrm{mg} \mathrm{C} / \mathrm{m}^{2} \mathrm{~d}$. The NPP peak estimated by the CbPM model appeared in 2008 and then drastically decreased. The trough appears in 2009-2011, with the highest value occurring in 2013.

In the eastern part of the northern fishing ground (Fig. 2b), interannual variability by VGPM model were mainly same with that by Eppley-VGPM. The values estimated by the two models generally increased from 2006 to 2008, decreased from 2009, and then rose again, The VGPM model peaked in 2011 and the Eppley-VGPM began to decline after 2010. The values of the two models continue to rise in 2013-2014 after reaching the trough in 2012. By 2015, values by VGPM model began to decline, while values by Eppley-VGPM model were still on the rise, which is similarities and differences of trend of inter-annual changes by the two models. Values of CbPM model had been reduced from 2006 to the lowest value in 2011, and then increased to 2015, began to decline. The daily NPP of annual average by Eppley-VGPM model is about 1.3 times the estimated value byVGPM model in the eastern South China Sea.

In the western part of the middle fishing ground (Fig. 2c), Estimated values by the three models were different obviously. The values by VGPM model reached the minimum value in 2010, NPP was the highest in 2011, and the estimated value in other years were concentrated in the range of $550 \sim 600 \mathrm{mg} \mathrm{C} / \mathrm{m}^{2} \mathrm{~d}$. Values by Eppley-VGPM model slowly declined from 2006 to 2008, increased from 2009 to 2010, and decreased over $60 \mathrm{mg} \mathrm{C} /$ $\mathrm{m}^{2} \mathrm{~d}$ in 2010, rising rapidly in 2011 and continuing upward in 2012. Values by CbPM model continued to decline from 2006 to minimum value in 2010 and after that rised to a small peak in 2012, and which changed one after another trend during 2012-2015.

The eastern part of the middle fishing area (Figure $2 d$ ), the VGPM and Eppley-VGPM models show a stable fluctuation within 10 years, and the basic trend is consistent. The NPP level is the lowest in 2010, but the Eppley-VGPM model has a higher value, which is 
about 1.8 times of values by VGPM model. Values by CbPM model began to decline from 2006 to 2011 to a minimum, 2012-2015 was fluctuating state, the overall trend is a decreasing trend.
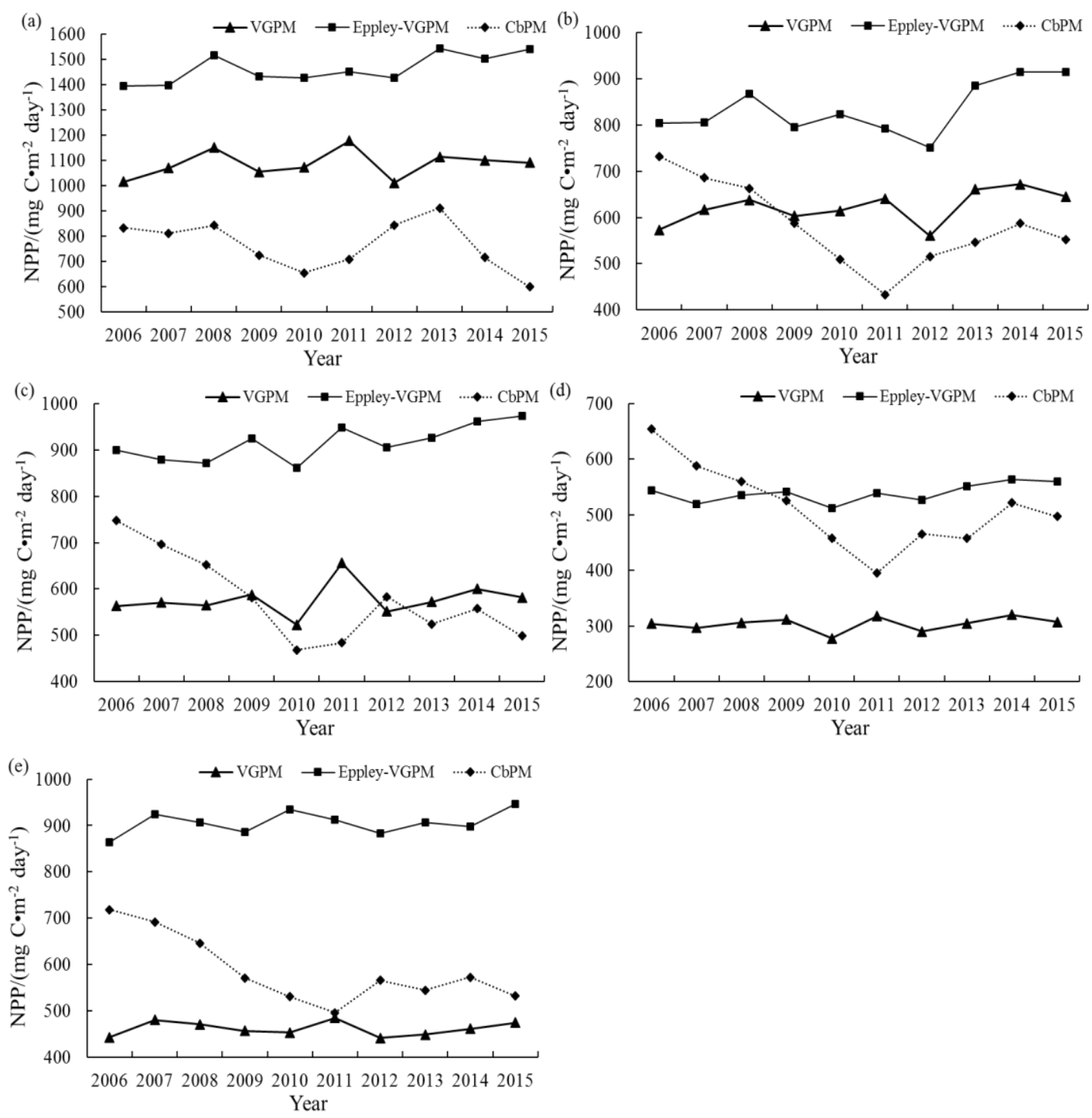

Figure 2. The interannual variation values of NPP average were compared in this figure for standard VGPM, Eppley-VGPM and CbPM models from 2005 to 2015 (letter a-c represent the studying area of western part of north fishing area, eastern part of north fishing area, western part of middle fishing area, eastern part of middle fishing area and southern fishing area, respectively, the same below in Fig. 3)

In the southern fishing ground (Fig. 2e), Values by VGPM model had no significant change within 10-year period except for a small peak in 2011, with NPP levels concentrating in the range of $440 \sim 480 \mathrm{mg} \mathrm{C} / \mathrm{m}^{2} \mathrm{~d}$, which were the lowest level in all models. The Eppley-VGPM model shows a steady-state fluctuation, with a decade-long 
NPP distribution of $860-950 \mathrm{mg} \mathrm{C} / \mathrm{m}^{2} \mathrm{~d}$, about twice the estimated value of the VGPM model. The trend of NPP in the southern fishing ground estimated by the CbPM model during 2006-2015 is consistent with that in the eastern and central fishery ground. Fig.2 showed that the annual mean value of NPP in the South China Sea, which was obviously regional, NPP levels were higher in the northern fishing ground than that in the southern and middle fishing ground, with the NPP values higher in the western region than that in the eastern region in the longitude direction.

In the west of the northern fishery area (Fig. 3a), the NPP in winter (December-February) is the highest in the VGPM model, decreasing gradually in the spring (March to May), decreasing in summer (June to August) to the lowest level, and begining to rise in autumn (September - November), which is the highest in winter, followed by spring and lowest in summer.The peak of NPP in the Eppley-VGPM appears in summer and the NPP reached the highest value in July. After September, it begins to decline slowly and reached its peak in winter, and the autumn was second only to summer. The CbPM model has the same seasonal distribution pattern as the Eppley-VGPM model, which is the highest in summer, followed by autumn and lowest in winter. In the east of the northern fishery area (Fig. 3b), the VGPM model estimates are highest in winter, followed by spring, and appropriate in summer and autumn, but the data shows that NPP gradually increases after September, and the lowest NPP is in the August and September. NPP in the Eppley-VGPM and CbPM models has a similarity over the course of a year, with similar peaks and troughs, peaks in summer and troughs in April and December. The difference is that the estimates of Eppley-VGPM is lowest in spring and the estimates of CbPM is lowest in winter. The estimates of other two models are very different. The estimates of Eppley-VGPM model is 1.4 times as the CbPM model.

In the west of the central fishing area (Fig. 3c), the VGPM model estimates are consistent with the NPP seasonal variation in the northern fishing zone, with the highest in winter, followed by autumn and the lowest in summer. The Eppley-VGPM model developed a valley and a peak from August to October, with the highest in autumn, followed by summer and the lowest in spring. The CbPM model has a similar trend to the Eppley-VGPM model during the one-year period. From July to September, NPP has a peak value, with the highest in summer, followed by autumn and spring in autumn. In the eastern part of the central fishing area (Fig. 3d), the VGPM model estimates is the highest in winter and lowest in summer, with a similar NPP in spring and autumn, only 270-280 $\mathrm{mg} \mathrm{C} / \mathrm{m}^{2} \mathrm{~d}$. The Eppley-VGPM model estimates do not reflect seasonal variations. CbPM model formed trough in September, with the highest in winter in the year, followed by spring, and the lowest in summer. In the southern fishing area (Fig. 3e), the VGPM model estimates is the highest in winter and NPP in the other seasons is generally in the range of 400 to $426 \mathrm{mg} \mathrm{C} / \mathrm{m}^{2} \mathrm{~d}$. Eppley-VGPM estimates are the highest in winter and NPP in the other seasons is not seasonal. The CbPM model estimates has a small peak in spring, followed by winter and the lowest in the autumn.

The spatial distribution of NPP estimated by the VGPM model is mainly composed of two low value areas and coastal high value areas and the maximum value is $3400 \mathrm{mg} \mathrm{C} / \mathrm{m}^{2}$ 
$\mathrm{d}$, the minimum value is only $250 \mathrm{mg} \mathrm{C} / \mathrm{m}^{2} \mathrm{~d}$, the estuary is the highest and deep sea basin is the lowest. The northern area of northern high value areas is mainly distributed in the northern Gulf of Leizhou Peninsula, the East and west coasts of the shallow sea and the Qiongzhou Strait, NPP decreases from north to south, the whole area of NPP were higher. The high value of North regions of eastern areas are mainly located in the Pearl River Estuary, northern continental shelf area, and decreased from north to south, forming a low value area in the west of the Luzon strait. In the middle western areas, high value areas are mainly distributed in the Mekong Delta region and the eastern continental shelf area of Vietnam, NPP decreased from west to East. Because the Middle East area is in the north deep basin area, forming a low value center, NPP is the lowest than other areas. The southern area of high value areas is mainly distributed in the Mekong River in southern Haikou, Western Malaysia continental shelf areas, the low value center is located in the South deepwater basin region.
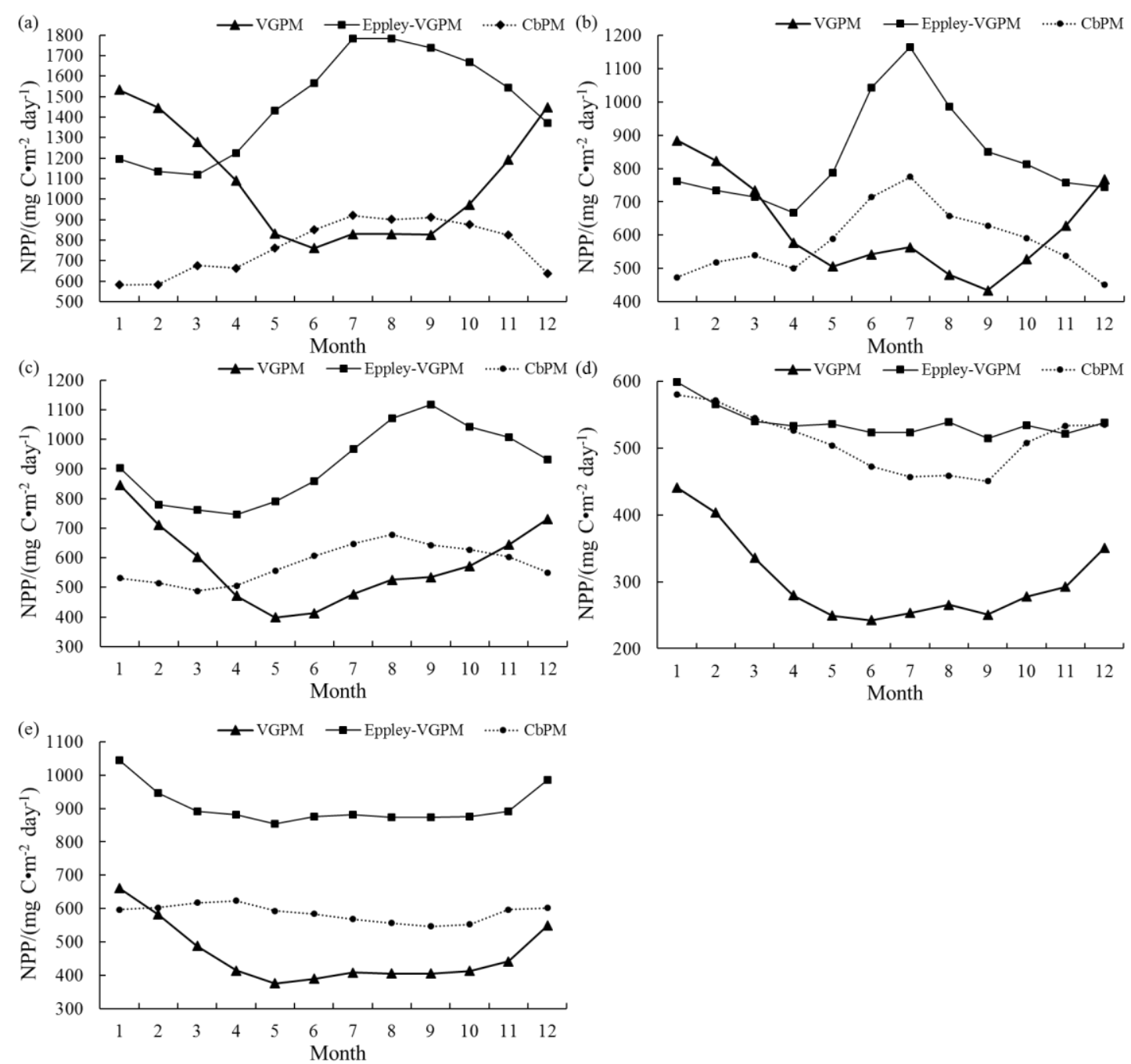

Figure 3. This shows a figure consisting of different seasonal NPP averages for standard VGPM, Eppley-VGPM and CbPM models from 2005 to 2015 
The spatial distribution of NPP estimated by Eppley-VGPM model is similar to that of VGPM model, but the estimated values are much higher than the other two models, the highest value is $5406 \mathrm{mg} \mathrm{C} / \mathrm{m}^{2} \mathrm{~d}$, the lowest value is $480 \mathrm{mg} \mathrm{C} / \mathrm{m}^{2} \mathrm{~d}$. On the north western area, in the whole Beibu Gulf region, the NPP is higher from the east and west coast of Leizhou Peninsula to the Qiongzhou Strait region. In the north eastern area, the NPP value of the Pearl River estuary is higher than nearby shelf area and decreases from north to south, forming a high value area in the vicinity of the Dongsha Islands and an obvious low value area in the west of Luzon strait. In the central area of western, the NPP near Paracel Islands is higher than the surrounding area, forming high value area in the Mekong River Estuary, East Vietnam shelf regin. In the Middle East area, most of the region is in low value area. In the southern area, the NPP of coastal area is higher than off the coast, forming a low value center in the southern deep water basin.
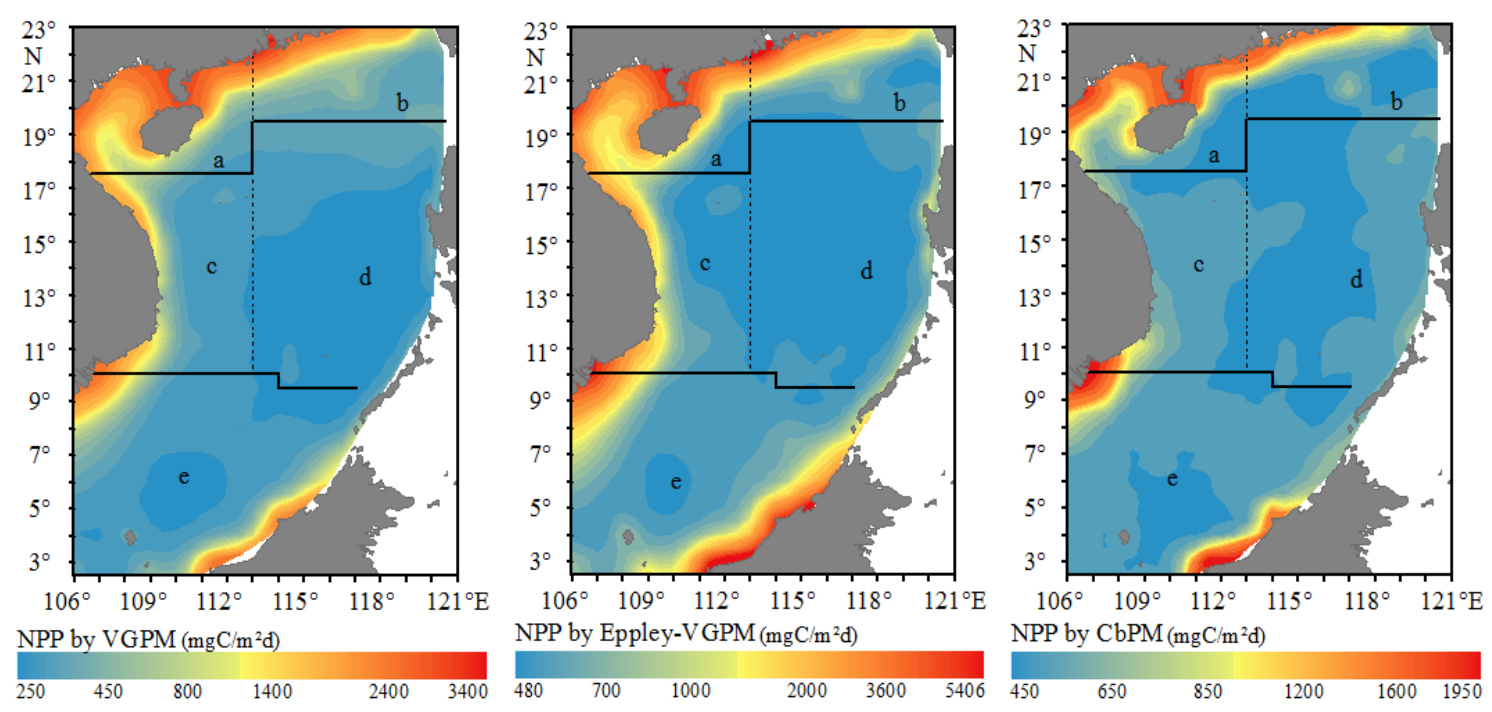

Figure 4. The figure exported by ArcGIS is about spatial distribution of high NPP and low NPP for standard VGPM, Eppley-VGPM and CbPM models within different fishing areas

The distribution difference of NPP which was estimated by CbPM model in space is also very obvious, the highest value is only $1950 \mathrm{mg} \mathrm{C} / \mathrm{m}^{2} \mathrm{~d}$, the lowest value is $450 \mathrm{mg}$ $\mathrm{C} / \mathrm{m}^{2} \mathrm{~d}$. In the north western area, the high value areas are mainly concentrated in the Leizhou Peninsula in the East and west coasts of the shallow sea and near the Qiongzhou Strait, reducing gradually from the coast to the central region in the northern Gulf. In the north eastern area, the NPP of the Pearl River Estuary is quite similar to that of the and northern continental shelf area, which is Significantly lower than the NPP near the Leizhou Peninsula, at the same time, there is a small high value center near the Dongsha Islands in the eastern and northern regions, and a low value area is formed on both sides of the east and west. In the central area of western, except near the Mekong River Estuary and the NPP of other regions is lower than that of the nearby continental shelf, on average at about $650 \mathrm{mg} \mathrm{C} / \mathrm{m}^{2} \mathrm{~d}$. In the deep basin region of central eastern area, it can be seen that 
there there is a large area of irregular low value area, which has a wide range of latitude. The southern area on the spatial distribution and the other two models to estimate the distribution of product the space is similar.

\section{Discussion}

The results above are obtained based on 10 years' average, but the differences are still very large. These differences show that the goodness of fit among products estimated by the three models in the SCS is low. Complexity of the SCS's ocean environment and diversities of algorithms are two main reasons for these results (Lee et al., 2015; Liu et al, 2012).

The SCS bounded by continent, gulf and some continental shelf., the largest marginal sea of China, is vast and rich in natural resources. Because of influence of the East Asian Monsoon and the Kuroshio Current, the upper ocean circulation of the SCS follows the change of monsoons (Liu et al, 2012; Ning et al., 2004). There are some complicated physical phenomena in the SCS, such as mesoscale eddies, coastal upwelling, typhoon and Runoff (Liu et al, 2012; Huang et al., 1992). These cause seasonal and spatial distribution of NPP significantly in the SCS. Strong regionalism and interaction between various factors increase the difficulty of estimating the SCS's NPP from remotely sensed data, which is one reason for the difference of NPP products in the SCS.

The estimated ocean NPP values in coastal areas are very high, especially estimated by the Standard VGPM and Eppley-VGPM, the maximum estimated by the two models are more than $3000 \mathrm{mg} \mathrm{C} / \mathrm{m}^{2} \mathrm{~d}$. The cause of the result may be related to that the two models all use chlorophyll concentration data as the input data to estimate NPP (Lee et al., 2015). There are some considerations for NPP values in coastal areas, two reasons: 1) on the one hand, coastal upwelling and river runoff can carry rich nutrients, promote the growth of phytoplankton and improve coastal NPP, 2) but on the other hand, river runoff can carry silt and make costal sea turbid, which can result in uncertainty of chlorophyll data precision. The CbPM adopts the ratio of chlorophyll and phytoplankton carbon (Chl: $C$ ) as input data to estimate NPP, this is the difference from other two models. Diversity of algorithms is another reason, lead to the inconsistency between NPP products estimated by the three models.

Fig. 2 showed annual averages fluctuated obviously during 2008-2012 within every fishing area. In the western and eastern parts of the north fishing area, it can be seen that the mean values of the three models in 2008 were significantly higher than those in 2007 and 2009, while there was no obvious fluctuation in other fishing areas. And the annual average values of each model had the lowest value in different fishing areas in different years. The results of VGPM and Eppley-VGPM models showed that the lowest year in the north, middle and south fishing areas were 2012, 2010 and 2012 respectively. And lowest value of the year by CbPM model in western part of north fishing area, eastern part of north fishing area, western part of middle fishing area, eastern part of middle fishing area and southern fishing area were 2010, 2011, 2010, 2011 and 2011, respectively. Related studies showed that La Nina event had occurred in the end of $2007 \sim 2008$, the 
end of $2010 \sim 2011$, the end of $2011 \sim 2012$ (Yu et al., 2016; Ji et al., 2015), and El Nino event had occurred in the end of $2009 \sim 2010$ (Yu et al., 2016). Although the specific impact mechanism needs to study in the further study, it can be concluded tentatively that the anomalous events have significant correlations with the interannual variability of NPP in the SCS (Yu et al., 2016).

Previous studies have shown that the seasonal variation of the primary productivity in the South China Sea is obvious, but the seasonal variation has strong regional characteristics (Liu et al., 2012). Due to the northeast monsoon in the northern of the South China Sea, the near-shore waters mixing is intense, and the mixed layer is deeper than the true light layer, so that the phytoplankton are frequently involved in or out of the true light layer, which is not conducive to photosynthesis (Le et al., 2008). Related studies also suggest that primary productivity is highest in summer, followed by winter and lowest in spring at the northern of the South China Sea (Qiu et al., 2008), Other studies have shown that primary productivity of the oceans near the coastal areas of Guangdong and Beibu Gulf is higher all the year around. Considering these two points, the Eppley-VGPM model can be initially considered to be more suitable for the west of the northern fishing area. In the west of the Luzon Strait, NPP is similar to the basin area in summer and it closes to the coastal area due to algal bloom phenomenon in winter. Therefore, the VGPM model is considered to be more suitable for estimating the NPP in the eastern of the northern fishing area. In the western of the central fishing area, the primary productivity in summer and winter is higher due to the presence of the eastern shelf and the Mekong River (Liu et al., 2012). And studies have shown the NPP level is the highest in winter at the eastern continental shelf area of Vietnam (Wang et al., 2015), while the summer NPP value estimated by the VGPM model was not as high as that in the previous studies. For these three models, the VGPM model is more suitable for NPP estimation in this region. In the eastern of the central fishery, the region is in a nutrient limited area because of the existence of the central basin. The positive correlation between the biomass of phytoplankton and organic carbon makes the backscattering coefficient of particles a better indicator to measuring the biomass of phytoplankton (Behrenfeld et al., 2005; Siegel et al., 2013). Meanwhile, the seasonal variation of the region is not obvious and NPP value is lower than the near shore (Liu et al., 2012). Therefore, it is more appropriate to use CbPM model to estimate the product for fishery application. The Southern fishing area is located in low latitude area and seasons change is not obvious, so the seasonal variation of NPP is not obvious (Wang et al., 2015); At the same time, the fishing area is located in the southern deep-water basin and in Mekong River into the sea. From the seasonal distribution of view, Eppley-VGPM and CbPM model products are suitable for the application of the region. And from the spatial distribution point of view, the Epple-VGPM model not only estimates the low-value areas of deep-sea basins but it can be seen in the Natuna is significantly higher than the surrounding basin, which is an advantage that CbPM model can be not reflected. Therefore, it is preliminarily concluded that the Eppley-VGPM estimation model is more suitable for the application in fishery area. 


\section{Conclusion}

The differences among the estimated ocean NPP products based on inversion data from the same sensors are very large, the level of the ocean NPP estimation from remote sensing based on algorithms need to be improved in other word. The complexity of algorithms, parameterization process, parameters precision, original input data and so on all can be as the research directions in the further study. Thus there is a requirement for detailed comparison to analyze the causes of these differences and improve algorithms and parameterization setting.

Acknowledgements. This research was funded by the Key Technologies R\&D Program of China (No.2013BAD13B06), National Natural Science Foundation of China (No.31602206), Natural Science Foundation of Shanghai (16ZR1444700), and Project NO.2016T05 Supported by Special Scientific Research Funds for Central Non-profit Institutes (East China Sea Fisheries Research Institute).

\section{REFERENCES}

[1] Behrenfeld, M. J., Boss, E., Siegel, D. A., et al. (2005): Carbon-based ocean productivity and phytoplankton physiology from space. -Global Biogeochemical Cycles 19(1):177-202.

[2] Behrenfeld, M. J., Falkowski, P. G. (1997): Photosynthetic rates derived from satellite-based chlorophyll concentration. -Limnology and Oceanography 42(1) :1-20.

[3] Campbell, J. W., Antoine, D., Armstrong, R., et al. (2002): Comparison of algorithms for estimating ocean primary production from surface chlorophyll, temperature, and irradiance. - Global Biogeochemical Cycles. 16(3), doi:10.1029/2001GB001444.

[4] Carr, M. E., Friedrichs, M. A. M., Schmeltz, M., et al. (2006): A comparison of global estimates of marine primary production from ocean color. -Deep Sea Research Part II Topical Studies in Oceanography 53 (5-7): 741-770.

[5] Chu, X., Fu, K. (2012): Planning and studies on the development of fishieries resources in the South China Sea via cross-strait cooperation. -China Ocean Law Review (2): 1-20. (in Chinese)

[6] Eppley, R. W. (1972): Temperature and Phytoplankton Growth in the Sea. -Fishery Bulletin 70: 1063-1085.

[7] Huang, Q. Z., Wang, W. Z., Li, Y. S., Li, C. W., Mao, M. (1992): General situations of the current and eddy in the South China Sea. - Advance in Earth Science7(5): 1-9. (in Chinese)

[8] Ji, S., Zhou, W., Chen, T., Chen, G. (2015): On the forecast and analysis of fishing grounds in the open South China Sea. -Fishery Information \& Strategy 30(2): 98-105. (in Chinese)

[9] Le, F. F., Ning, X. R., Liu, C. G., Hao, Q., Cai, Y. M. (2008): Standing stock and production of phytoplankton in the north South China Sea during winter of 2006. - Acta Ecologica Sinica 28(11): 5775-5784. (in Chinese)

[10] Lee, Y. J., Matrai, P. A., Friedrichs, M. A. M., et al. (2015): An assessment of phytoplankton primary productivity in the Arctic Ocean from satellite ocean color/in situ chlorophyll-a-based models. -Journal of Geophysical Research Oceans 120(9): 6508-6541.

[11] Lee, Z., Marra, J., Perry, M. J. et al. (2015): Estimating oceanic primary productivity from ocean color remote sensing: a strategic assessment. -Journal of Marine Systems149: 50-59. 
[12] Liao, Y., Lü, D., He, Q. (2014): Intercomparison of albedo product retrieved from MODIS, MISR and POLDER. - Remote Sensing Technology and Application 29:1008-1019. (in Chinese)

[13] Liu, H. X., Song, X. Y., Huang, H. H., Tan, Y. H., Huang, L. M. (2012): A comparison study on primary production in typical low-latitude seas (South China Sea and Bay of Bengal). - Acta Ecologica Sinica 32(18): 5900-5906. (in Chinese)

[14] Morel, A. (1991): Light and marine photosynthesis: a spectral model with geochemical and climatological implications. -Progress in Oceanography 26(3): 263-306.

[15] Ning, X., Chai, F., Xue, H., Cai, Y., Liu, C., Shi, J. (2004): Physical-biological oceanographic coupling influencing phytoplankton and primary production in the South China Sea. - Journal of Geophysical Research 109, C10005, doi: 10. 1029 /2004JC002365.

[16] Qiu, Y.S., Zeng, X.G., Chen, T., et al. (2008): Fisheries resources and management in the South China Sea. - China Ocean Press, Beijing. (in Chinese).

[17] Saba, V. S., Friedrichs, M. A. M., Antoine, D., et al. (2011): An evaluation of ocean color model estimates of marine primary productivity in coastal and pelagic regions across the globe. - Biogeosciences and Discussions 7(5): 489-503.

[18] Saba, V. S., Friedrichs, M. A. M., Mary-Elena, C., et al. (2010): Challenges of modeling depth-integrated marine primary productivity over multiple decades: A case study at BATS and HOT. -Global Biogeochemical Cycles 24(3):811-829.

[19] Siegel, D.A., Behrenfeld, M.J., Maritorena, S. et al. (2013): Regional to global assessments of phytoplankton gynamics from the Sea WiFS mission. - Remote Sensing of Environment 135: 77-91.

[20] Wang, X.Q., Xing, X. G., Wang, J. P., et al. (2015). A satellite- based analysis on the seasonal variations and inter-relationships between chlorophyll and particle in the South China Sea. - Haiyang Xuebao 37(10): 26-38. (in Chinese)

[21] Westberry, T., Behrenfeld, M. J., Siegel, D. A., et al. (2008): Carbon-based primary productivity modeling with vertically resolved photoacclimation. -Global Biogeochemical Cycles 22(2), GB2024, doi: 10.1029/2007GB003078.

[22] Xu, H.Y., Zhou, W.F., Li, A.Z., Ji, S.J. (2017): Similarities and Differences of Oceanic Primary Productivity Product Estimated by Three Models Based on MODIS for the Open South China Sea. - In: Yuan, H., Geng, J., Bian, F. (Eds) „Geo-Spatial Knowledge and Intelligence" 4th International Conference on Geo-Informatics in Resource Management and Sustainable Ecosystem, GRMSE 2016, Hong Kong, China, November 18-20, 2016, Revised Selected Papers, Part I, Springer Nature.

[23] Yu, W., Chen, X., Yi, Q. (2016): Relationship between spatio-temporal dynamics of neon flying squid Ommastrephes bartramii and net primary production in the northwest Pacific Ocean. - Acta Oceanologica Sinica 38 (2): 64-72. (in Chinese)

[24] Zhang, J., Chen, Z. Z., Chen, G. B., et al. (2015): Hydroacoustic studies on the commercially important squid sthenoteuthis oualaniensis, in the South China Sea. Fishery Research 169:45-51. 